\title{
Research on the Social E-commerce Marketing Model Based on SICAS Model in China
}

\author{
Xiao-Xu Yan ${ }^{1}$, Zhong-Qi Hu${ }^{2}$, Jie Xu ${ }^{1}$ \& Jing-Yan Liu ${ }^{1}$ \\ ${ }^{1}$ International Business School of Jinan University, Guangdong, China \\ ${ }^{2}$ School of Translation Studies of Jinan University, Guangdong, China \\ Correspondence: Jing-Yan Liu, International Business School of Jinan University, Guangdong, China. E-mail: \\ silentrock@foxmail.com
}

Received: March 10, 2017 Accepted: May 10, 2017 Online Published: May 29, 2017

doi:10.5539/ijms.v9n3p113 URL: http://doi.org/10.5539/ijms.v9n3p113

\begin{abstract}
With the appearance of the Internet and the further escalation of consumption, a growing number of individuals paid attention to expressing their emotions by commenting, sharing, interacting and so on, for spiritual satisfaction when they were shopping rather than barely pursuing the efficiency. As a result, deeply composed with the social media technologies and the e-commerce, social e-commerce is round the corner. Based on the previously theoretical research and the SICAS consumption model, this paper analyzed the decision-making process of consumers in the era of social e-commerce in detail at first and afterward creatively put forward the ICES marketing strategy model of social e-commerce. Finally we took Red, a social e-commerce company as the subject investigated, using the proposed marketing strategy model to analyze the marketing strategies of Red. The result illustrates that this marketing model has high applications' value and it can be used for reference for the domestic and foreign social electricity supplier enterprises.
\end{abstract}

Keywords: social e-commerce, marketing mode, SICAS model, red

\section{Introduction}

In the mobile internet era, the e-commerce is faced with many problems such as the homogenization, the intense competition and so on, and the market growth starts slowing. With the social media technology and e-commerce deeply integrating, a new derivation of e-commerce, social e-commerce receives an increasing number of attentions of business circles and the academia.

In the December 2015 Yahoo! first proposed a new e-commerce mode named social e-commerce, nevertheless, scholars did not start to study this new business model until 2007. As a matter of fact, there were still many controversies over the definition of "social e-commerce" in the academia. Many scholars hold the view that social e-commerce was a new form of e-commerce. For example, Afrasiahi Rad \& Benyoucef (2011) thought that social e-commerce was a specific form of e-commerce based on personalizing and interactively social connections. Kang \& Park (2009) inclined to the view that social e-commerce was a new form of e-commerce but social e-commerce attached great importance to more about the discussion between consumers, commodity evaluations or possibilities of service. Other scholars thought that social e-commerce was a process which employed the social media technology to influence consumers' making purchase decision, and their emphasis was the influence which social media technology brought to business activities. Marsden (2010) thought that social e-commerce used social media technology to impel the interactions between consumers and enterprise so that it would improve the shopping experience of consumers. In the China social e-commerce Report 2011, iResearch, a professional market research institution in China, thought that "social e-commerce is a phenomenon that it applies the concerning, sharing, communicating, discussing, interacting and other social elements to the process of e-commerce". According to the above researches, referencing the research results of Xiaodong Zhu \& Jie Chen et al. (2016), this paper thought that social e-commerce was a new e-commerce that used social interactions, user-generated contents and other methods like these to assist merchandise sales and sales behavior by the social networking site, social media, network media and other transmission routes in the social media context. 
The social trend of e-commerce also promotes the change of marketing model. The traditional e-commerce business's marketing emphasis is the shopping activity of consumers and it supplies advanced functions such as searching, catalogue, one-click approach, personalized recommendation to maximize consumers' shopping efficiency. With the appearance of Internet, more and more people paid increasing attention to express their emotions by commenting, sharing, interacting and so on, for spiritual satisfaction when they were shopping rather than only pursuing the efficiency. The consumers' decision-making behavior has a tremendous change, from the AIDMA model to the AISAS model and now transforming into the SICAS model, and the effect of traditional e-commerce marketing model is tapering. So social e-commerce enterprises should focus on the social contact and encourage the sharing and interaction between consumers so that they can satisfy the spiritual needs of consumers and facilitate the deal at last for adapting the changes of the consumer behavior.

In view of the above, this paper will make a detailed study about social e-commerce marketing model. Firstly it will summarize previous scientific research and introduces the SICAS consumption model to analyze today's consumers' decision making process. Subsequently it proposes the social e-commerce marketing model according to the stage of consuming behavior. Finally we will take Red, a social e-commerce company, as the research objective through the new marketing model to analyze the marketing model of Red. The research of the social e-commerce marketing model will has a highly guiding significance for e-commerce enterprises using social media to start social marketing.

\section{Literature Review}

With the Internet developing deeply, the social media wildly incorporating into our life, social e-commerce started coming in to our view as a new business model and an increasing number of scholars paid attention to the new business model. The hotspots in recent researches can be roughly classified into four types. The results are systematically summarized as follows.

\subsection{Research on Business Model of Social E-commerce}

The research of business model is always an important difficulty in social e-commerce. Wu Juhua (2014) emphasized the comparison between the changes of business model and value chain of social e-commerce and traditional e-commerce and summarized the innovation point of business model social e-commerce. And Jiena $\mathrm{Li}$ (2014) combined the basic model with correlation theory of consumers' information behavior and set up a social e-commerce. It is a model of social e-commerce shopping process for analyzing model of social e-commerce from the point of information behavior. Other scholars studied the typical business model of social e-commerce enterprise by case study method. Liu Liuxin (2012) compared the three exiting forms of social e-commerce, selected the typical representatives of four Chinese social e-commerce platforms' models, and discussed the strategic positioning, business model and profit mechanism of social e-commerce enterprise in depth.

\subsection{Research on the Impact of Social E-commerce on Consumer Behavior}

With the social media developing, more and more research found that social media influenced consumers' decision-making behavior deeper and deeper. In the social e-commerce Today, Marsden (2009) thought that transaction was more and more coming from socialization relationship and the Internet had a strong driving force for personal shopping advice. It not only has the driving force, but it will also influence customers' decision making process directly. And Kim \& Srivastava (2007) analyzed the impact of social networks on e-commerce decision making and summed up e-commerce website using the social influence to help consumers to make decision. In social e-commerce era, opinion leader also plays an important role in influencing the area of consumer behavior. Fei Meng (2012) studied that in social e-commerce environment the impact of opinion leader on consumer behavior based on theory of consumer behavior, technology acceptance model, theory of perceived value and the trust theory. The research showed that customers would accept the opinion leader which has similar product preferences, interests and tastes with theirs and had purchase intention.

\subsection{Research on the Dissemination Effect of Social E-Commerce}

Social e-commerce mainly relied on social media for disseminating. So many scholars focused on studying social e-commerce from the view of dissemination. Juan Jiang (2012) studied Chinese the dissemination of social e-commerce from the view of dissemination science and the res shows that in our social e-commerce activities consumers participation behavior is not active and most consumers community behavior were browsing information and retransmitting information. Word-of-mouth is the most important route of transmission. Wenqian Chen (2013) selected social e-commerce as the research objective and analyzed the strategy and the pros and cons of word-of-moth based on cases of MOGU Street and Meilishuo enterprises 
which have the best development in recent years. She hoped to get quit a few ideas for social e-commerce enterprise from the view of dissemination effect.

\subsection{Research on the Marketing Mode of Social E-commerce}

As a new business model, social e-commerce also promotes the change of e-commerce enterprise's marketing model. More and more scholars begin to focus on the view of marketing mode. A Srivastavaand KM Pandey (2013) strategically analyzed the impact of social media on e-commerce and proposed to coordinate and integrate the concrete strategy for social media marketing. Mata \& Quesada (2014) discussed the importance of online social network in marketing and combined with practice to discuss the practical application of social network in social e-commerce marketing. China is successful in the practice of social e-commerce but the theoretical research lags behind. Hui Li (2014) studied the social e-commerce marketing of Tencent in depth by case analysis and analyzed the characters of Tencent's social e-commerce marketing. There were also some scholars summarizing regularities from the strategic level. Zhang et al. (2014) carded and summarized marketing innovation regulars of strategic design, socialization tactics, trajectory position, self-diagnosis and future developing engine in the development of social e-commerce.

In conclusion, academia has a strong independence in studying social e-commerce and this paper will study it deeply by combining consumers' consuming behavior with marketing strategy, analyze consumer decision making process according to Models of consumer behavior and propose marketing strategies pertinently based on these and hope to fill the blank of academic research.

\section{Theoretical Basis}

The core of marketing is grasping consumers' psychological need. Understanding patterns of consuming behavior plays a significant role in deciding marketing direction. In WEB2.0 and mobile internet era, based on social network, between consumers, consumers and enterprises can be mutually connected and they can also make free dialogue. Consumers not only can actively obtain information from social networks and contacts scattering the entire network and they can also become consuming sources and main parts of publishing information and experience and share with more friends. With the change of communication environment and consumer behavior, consumer decision making process is also changing.

In 2011, Monitoring Research Institute\& DCCI (Data Center of China Internet) issued 2.0+ mobile Internet era of all digital consumption trajectory model-SICAS model. SICAS experiences sense, interest\&interactive, connection\&communication, action and sharing these five stages. Each stage connects with other four stages, which is regarded as the key point of the model. A detailed description of each stage is shown below.

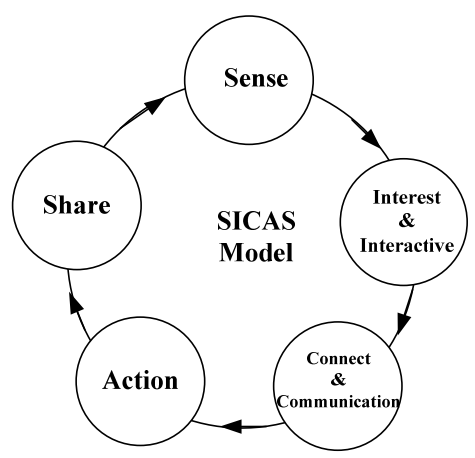

Figure 1. SICAS Model

\subsection{Sense}

In social media era, social network, mobile internet, LBS Location Based Services, MicroBlog and other social platforms can be used as a sense network between brands and consumers. As consumers, they can choose the brands which they are interested in to follow anytime and anywhere. And as enterprises, they can use sensors to scatter in the entire network for finding the experience comment of consumers.

\subsection{Interest \& Interactive}

After choosing the right marketing communication method and creating a strong interest in consumers, the effective interaction can be brought between brands and consumers. The traditional marketing communication 
methods are no longer effective but understanding, following and influencing the interest and needs of consumers are becoming the key to success.

\subsection{Connect \& Communication}

Between brands and consumers, a connection should be gradually established from weak to strong and achieve a connection and communication between differently advertising systems and content-service systems. Enterprise should stand from the point view of consumers, establish adequate communication mechanism and deepen the consumer's familiarity with the brand.

\subsection{Action}

In social media era, consumers gradually changed their purchase methods. With the popularity of the online shopping mall like the WeChat shop and other e-commerce sites, more and more consumers chose shopping online. Meanwhile, the consumers required higher and higher purchasing experience.

\subsection{Sharing}

Openness and sharing, the two characters of social media can make fragmented consumer experience produces spontaneous dynamic polymerization. Experience and sharing are not the end of purchasing decision making behavior but the origin and source of a newly purchasing decision making behavior and it becomes an important source of consuming productivity.

\section{Social E-commerce Marketing Model based on SACAS Model}

With the further development of Internet, the homogeneous trends of traditional e-commerce enterprise marketing mode became more and more terrible. Unilateral reliance on advertising for "price war" can be difficult to attract consumers and create higher trading volume. Consumers aspire more of commodity's added value beside on its use value and pay more attention to satisfy their emotions and ascription needs and self actualization needs. Social e-commerce satisfies consumer demand and as a new model it makes the best of social network to promote following, sharing, discussing and interacting of consumers. All of these can facilitate the deals. This change of business model is leading the change of marketing mode. Marketing mode will change from the traditional one-way transmission to the two-way interaction even multiparty interaction, from paying attention to the marketing effect to the consumer needs, from aspiring quantity to quality of marketing.

In social e-commerce era, in the process that consumers sense, have interest in, communicate and interact with, purchase and share the product and brand, social media and social software both full play to the function of carrier and continuously transmit the enterprise information. But the key point of a successful marketing strategy is using the social relationship and social network to have a targeted marketing in each stage of consumer decision making. Therefore they can firmly grasp the needs of consumers, greatly enhance the marketing effect and enhance customer satisfaction and loyalty.

So based on the SICAS consumer behavior model, this paper proposes a new social e-commerce marketing model-ICES model and we hope to provide theoretical direction for social e-commerce enterprise making marketing strategy. The framework of the model as shown in Figure 2, which is composed of four parts that are content marketing, interactive marketing, experience marketing and sharing marketing.

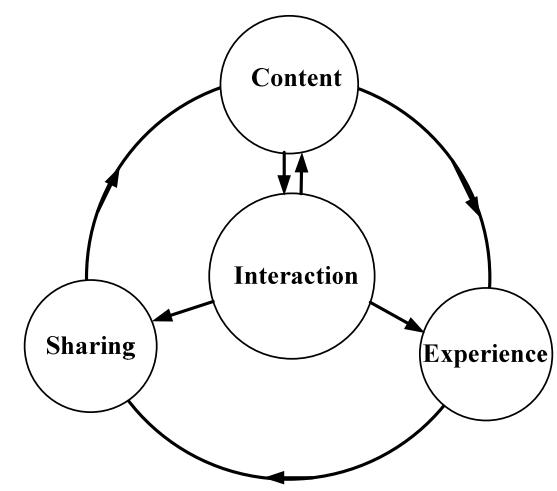

Figure 2. Social e-commerce model based on SICAS model (ICES model) 
As shown in figure 2, the four independent parts are connected with each other in fact. And the key point of the model is that it systematically integrates four sections of marketing and makes the effect of marketing mix maximizing. Firstly, social e-commerce enterprises can make consumers sense the information of the product and the brand and generate interest and purchasing desire by using content marketing. Then social e-commerce enterprise can promote consumer to achieve the purchasing behavior by using the experience's marketing strategies. Finally, enterprise can stimulate the consumer to share the shopping experience, impression and so on. And the sharing will attract other consumers to make new sense. The marketing model will cycle from this section again and all of these will be a closed cycle in business.

"Interaction" as an important content is bond up with other three sections of social e-commerce marketing. High-quality content is the basis of interaction and provides material for interaction. Meanwhile, the interactive process will produce many contents to enrich the original content further and add the interest and trust of consumers. In the process of experience marketing, interaction can increase shopping efficiency and optimize shopping experience. As a part of interactive marketing, sales promotion can also promote the occurrence of consumer's purchasing behavior directly. In addition, a series of interaction not only can satisfy their social needs, but it can also strengthen consumer's sharing desire in the sharing process. So the "Interactive Marketing" plays an important role in each section of the business closed cycle.

Thus it can be seen that the four parts are interrelated and indispensable and they combine the complete marketing mix. However, the maximized effect of the model needs completely carrying out each section. The following part will introduce how to achieve the successful marketing in each section in detail.

\subsection{Content Marketing}

Social e-commerce era is an era that content is king. Because the high-quality content is a basis that consumers can sense the product and brand, get interest in and communicate. For content, only if the enterprises achieve useful, beneficial, interesting, "the three" principle and produce the content that consumers love, they can make the content producing, content sharing, consumer adherence and commercial realization be really implemented. We consider that the successful content marketing of social e-commerce contains three sections: the first one is extending the content source. Traditional e-commerce marketing took the enterprise as the subject and its marketing content also took PGC (Professionally-generated Content) as the subject. In mobile Internet era, consumer is not satisfied with negative reception of information but to aspire creating content actively and share their emotions. So the enterprise should gradually achieve "decentralization" and encourage the consumers to create content. UGC (User-generated Content) not only can gratify consumer's social needs, but it also can fill the product information, add consumer truth and promote the fast information dissemination. Therefore, UGC should be encouraged.The second one is presenting various forms of content. E-commerce enterprise can present their products from words, pictures, videos, link pages, lives and other propaganda methods. The enterprise should also combine in marketing innovation, and deliver product connotation from many dimensions, so as to bring the additive effect to brand communication and ignite consumer interest. The third one is creating hot topics and contents. The enterprise can create word-of-mouth topics which are imaginative and connect with the product and band and use the interpersonal communication network of social media to spread as viral style for attracting the maximum range of consumer concerns. Through the above content marketing strategy, it can not only satisfy the society needs, promote the consumers' senses and ignite interest, but it can also spread the information of the product and the brand rapidly.

\subsection{Experience Marketing}

After the consumers sensing, being interested in and being connected with brand information, the most important affair is action that means purchasing. Whether traditional e-commerce or social e-commerce, the consumer's purchasing is the most important part and the purchasing experience can affect the consumer's purchasing behavior directly. So the experience marketing has extraordinary significance. Specifically, experience marketing is that the enterprise provides high-quality experience activities in the whole stage of consumer's purchasing activities. The difference from the traditional e-commerce is that the purchasing experience of social e-commerce is more complete, consumer-centric and it incorporates more social elements.

The experience marketing of social e-commerce should endeavor in three aspects. The first one is the experience of consuming process. Social e-commerce enterprise should provide a safe, convenient, fluent and trust worthily consuming process. Consumers even can share the shopping link through social media and software. And they can achieve one-click approach, which greatly facilitates the dissemination of products and consumer purchase. The second one is the experience of the product itself. Social e-commerce enterprise should pay more attention to the commodity description, logistics, package, product quality, relevant accessories and other aspects. The most 
plentiful social element is the strategy of packaging. Personalized and anthropomorphic package passes different value proposition interacting with consumers and triggering the emotional response of consumers. The third one is the experience of beyond expectation. Social e-commerce enterprises use the social media to bring all kinds of surprises to consumers and increase consumer's good impression. E-commerce brand increases the consumers 'understanding of the product by free trial so as to increase purchase rate. Also, the e-commerce platform itself can give away presents to increase the good brand impression of consumers. The experience of beyond consumer's expectation will bring a nice effect to guide consumer to purchase, develop dissemination and shaping reputation.

\subsection{Sharing Marketing}

The traditional e-commerce enterprise thought that the occurrence of consumer's purchasing behavior means the effect of marketing and the end of the marketing activities. But in social e-commerce era, the occurrence of purchasing behavior is not only the end of the marketing activities but it also means the beginning of marketing. Maslow's hierarchy of needs proposed five unities that they are physiological needs, safety needs, love and belonging, respect and self actualization and it means everyone has their own instinctive sharing needs. Human is the gregarious animal and they all require finding belonging and respect. And this kind of sharing based on the Internet can give them belongingness and respect. Consumer's instinctive sharing motivation is the basis and a more important thing is that social e-commerce enterprise should create a condition to encourage the content producing and quickened the dissemination of sharing content. Our model thought that social e-commerce enterprises should make more efforts in three aspects for promoting consumer's sharing and forming the word-of-mouth. The first aspect is setting up a platform for consumer sharing. The enterprise can sets up community based on the interest to provide a platform for liked, comment and interaction between consumers. The sharing process should be also convenient. The second aspect is playing a role of social tagging. The content what consumers share online may not be the true one, but they must want to be the image which is the sharing presenting and want to be identified as that image. So whether the product information or the PCG, it must have a sharp social tagging and guide the consumer dissemination. The third aspect is rewarding sharing. E-commerce enterprise can take a method of rewarding points to encourage the consumer sharing their shopping experience by words, pictures, links and any other forms. Open sharers can get the presents or the discounting preferentially.

Consumer's sharing behavior can not satisfy their social intercourse and belonging needs, but they also produce many UGC in the process and have a widespread. It can raise the sense, interest, following and trust and it also means the beginning of a renewed "content marketing". As a result, our marketing model becomes a completely closed cycle. This closed cycle will continuously attract new consumers, increase the loyalty of old consumers and promote the occurrence of consumer's sense-interest-communication-action-sharing behavior. This kind of marketing model is opening and continuable and the product and brand influence will continue to rise because of sharing.

\subsection{Interactive Marketing}

In social e-commerce era, consumers do not need accept information passively but accept and pass information in the interaction between consumer and enterprise. The quality of interactive marketing has an impact on the effect of other marketing strategies in a large extent. It also influences the purchasing behavior directly or indirectly.

In social commercial era, interactive forms between enterprise and consumers have a number of growths. E-commerce enterprise can use the "centralized" and "decentralized" interactive way in the process of interactive marketing. There are three mainly interactive forms in social era. The first one is the interaction between consumers and products and brands. E-commerce enterprise can introduce entertainments that consumers can take part in such as the H5 Mini-game marketing, lottery drawing, holiday promotion and any kinds of business activities. These interactive activities can improve the close connection between enterprises and consumers and add consumers' good opinions of the products and brands. The second one is the interaction between consumers and celebrities. Specifically the e-commerce enterprise can play a role of opinion leader and celebrity effect in social media. The information of opinion leader and celebrity has an important guidance to consumers. And it will add the consumer's purchasing interest imperceptible, promote the contact between consumers and enterprise and increase trusting contacts. The third one is the interacting between consumers and consumers. The e-commerce enterprise sets the community based on the common consumers' interest and encourages consumers who take part in the community to communicate with others, comments and recommend products and share their shopping tips and even their emotion and experience. The community in which consumers has a strong cohesion and experiences of consumers themselves will earn other consumers' trust. Therefore the community has higher conversion rates. The social e-commerce enterprise has an Omni-directional communication with consumers by using the above 
three interactive forms. And it can not only add the consumers' good opinion, encourage consumers' sharing and purchasing behavior but attracts new consumers in the continuous process of spreading the interactive content.

\section{Case Studies}

In this part, we will take the Red which is a successful social e-commerce enterprise as the subject investigated and use the social e-commerce marketing model proposed in preceding text to analyze the successful marketing experience of Red and further improve the model.

\subsection{Case Introduction}

Red is a social e-commerce platform which devotes to find the high-quality goods for consumers (shop the world) and established by Wenchao Mao and Fang Zhai in June 2013. The two major segments in Red are the community of overseas shopping in UGC (User Generated Content) model and cross-border e-commerce "welfare community". It is aimed at designing a platform to provide shopping information overseas to consumers and let consumers share their shopping needs and experience.

Red's platform collects the experience of shopping masters from everywhere and provides detailed tips for shopping which contain tax rebates, discount and travel information in different countries, special goods recommendation in different brands, shopping malls and their maps and the useful information in the local. Under B2C self-management model Red welfare community cooperates with overseas brands and large-scale traders directly and delivers to consumers using the bonded warehouse and overseas direct mall. In the course of the half year that the welfare community went online its sales volume reached more than 100 million dollars. Until October 2016, Red has cumulated 3.2 million consumers.

Red's target consumers are women between the ages of 20 and 40 who are mainly students and white-collars from big cities like Beijing, Shanghai and Guangzhou. They have great purchasing power, require high-quality lifestyle, heavily dependent on social network and take delight in expressing and sharing.

\subsection{Analysis of Red's Marketing Mode}

After Red moving into e-commerce it become an industry leader in the area of overseas e-commerce platform in less than a year and a half and its success much depend on its successful social marketing strategy. In the following text we will take the social e-commerce ICES marketing model based on SICAS model as the framework to sum up and analyze the marketing strategy of Red.

\subsubsection{Producing High-Quality Content and Creating Hot Topics}

Red is a content e-commerce enterprise which develops based on the communityof shopping sharing and uses decentralized UGC model. Consumers can share any kinds of tips such as the experience of overseas shopping, travel guides and shopping experience. These tips with pictures, words and even videos often have various forms and relevant evaluation of commodities. Other consumers can read, comment, like, collect and share these tips. Red's backstage can screen high quality tips out automatically for producing high-quality content. The content in the community always follows the social hotspot and connects with many current activities. So consumers often feel that they are going shopping in the malls when shopping on Red and they can listen to others' stories and feel more relaxed when they read these tips. The UGC model gratifies consumers' social needs, attracts many consumers and promotes consumers' information sense and interest to the product greatly.

Red also increases consumers' sense and interest by creating hot topics and adequate exposure. Red sets a series of marketing mix about hot topics for increasing its brand's visibility. Taking the anniversary activities to name only a few, Red started advertising through video which shows many topless new stars form every country and print advertisement in 25th May 2015. The video fully embodied the Red's slogan — shop the world through a sexy atmosphere. Starting in 1st June, the activity was continuous active because of the booming marketing activities and dissemination of new media and peaked on the anniversary in 6th June. Red launched an offline activity in which male models from foreign countries sent the express delivery at the same booming-sales time. And it also launched another marketing activity named "campus beau sending express delivers" in 12 domestic universities aimed at post-90s generation college students in September 2015. During just 3 months, all kinds of information of Red were refreshing many social platforms like Weibo and Wechat moments. The figure 3 is the trend graph of the Red's Baidu Index in 2015 and the peak is the booming reflection which produced by a series of marketing activities in the above text. The viral dissemination of hot topics increased Red's effect rapidly and there were many consumers beginning to focus Red and fall in love with it. 


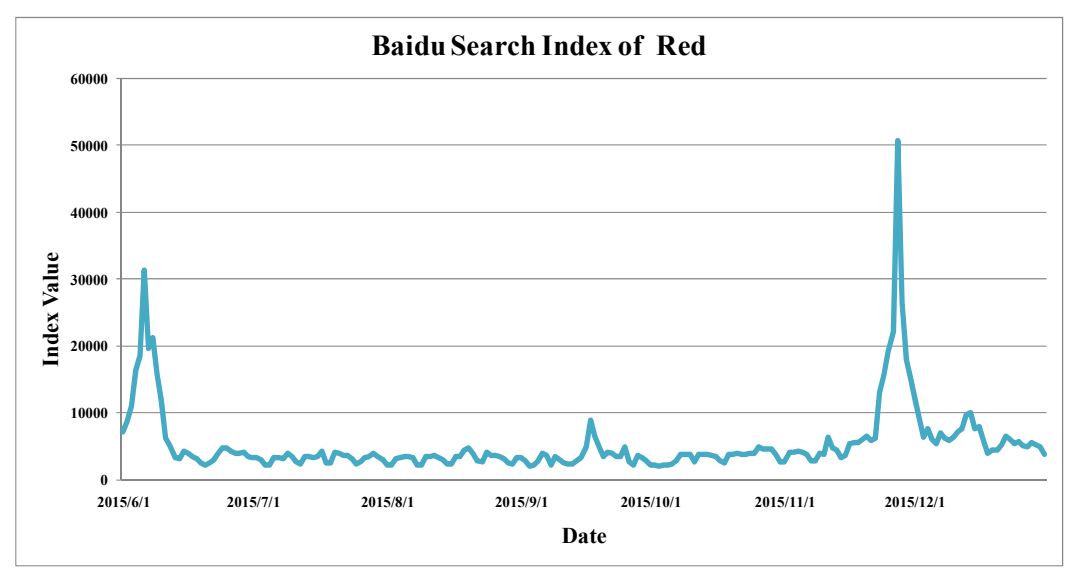

Figure 3. Red's Baidu search index

\subsubsection{The Satisfactory Shopping Experience}

The purchasing section is the most important section for social e-commerce enterprise. And the satisfactory shopping's experience which Red provides to consumers reflects in the efficient and convenient purchasing process and the high-quality product itself. From the beginning Red focused on perfecting mobile terminal because the mobile terminal is easier and more convenient than the PC terminal and it is easier to create sharing content for women who pay more attention to the time efficiency. Meanwhile, Red combines these contents with shopping links that eliminates the sense of violation, achieves "what you see is what you get" and one-chick approach. These humanized purchasing processes increased the conversion rate greatly and decreased losing consumers.

The experience of Red's product itself includes high-efficient logistics, quality of a genuine article, personalized package and so on. Another thing we must mention is the packaging strategy of Red. With the high-quality material, Red's express boxes were designed really beautiful whose red outlook was in complete harmony with the brand. The most brilliant part is the slogan. Its slogan is not only humorous but contains emotional and socialized elements which can arouse the emotion sympathy of consumers, bring satisfactory purchasing experience and promote online social sharing and communication.

\subsubsection{Establishing Word-of-Mouth in Sharing}

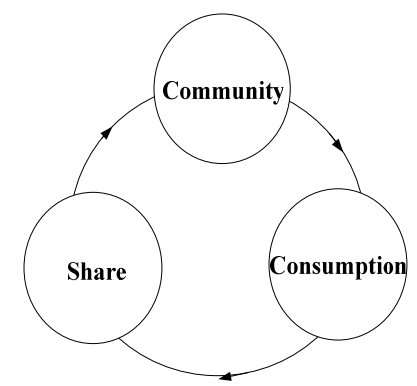

Figure 4. Closed marketing cycle of Red

Actually, Red worked on products and brand information dissemination and word-of-mouth marketing in all the process of creating hot topics, interactive marketing and shopping service. Fundamentally, its successful word-of-mouth marketing is still based on the sharing community model and it is also the core competitive edge of Red as a social e-commerce enterprise. On the one hand, Red sets up the sharing communities according to different interests and gives them social tagging. On the other hand, it encourages consumers to buy products and service, share experience about using and play a role of word-of-mouth by rewards like e-voucher. The most important thing is the consumers' purchasing behavior based on sensing the sharing content and consumers encouraged to express their own opinion in the community and social media, take part in the interaction and attract other consumers. These UGC model is the core component of its content marketing. As shown in Figure 4, sharing, 
community and consumption intertwine together and become a complete marketing closed cycle. These communities will attract more and more consumers and the sharing will contain more and more rich contents. And then the word-of-mouth effect will emerge and it will raise a series of sense-interest-communication-action-sharing behavior. The enterprise products and brand influence and sales volume will increase continuously.

\subsubsection{Full Range of Interactive Marketing}

The interactive marketing of social e-commerce enterprises is going on all the time. If they want to establish a good connection with consumers, increase consumers' loyalty and promote consumption and sharing, they should keep continuous interactive process. And Red did the best about this point. It achieved an omnibearing interaction between consumers, consumers and enterprise and between consumers and celebrities.

Red set up classified sharing community based on different interests, so consumers could read tips, share experience, comment and like and fully exchange their opinions in different kinds of communities such as food, sport, skincare and fashion. They can also follow their favorite open sharers and interact with them. Furthermore, Red also hosts regular games and holiday promotions such as the "guess questions, win red packets" in 2017 Spring Festival and that increase the communication between enterprise and consumers. Not only that, Red created the condition for consumers communicating with celebrities such as the activity named "Ge Hu spends the whole three days together with Red". Ge Hu is a famous actor and singer in China and he has lots of young female fans. On the third anniversary in April 2016, Red shaped "Ge Hu" as a "ordinary consumer" and provided a platform for him to interact with consumers and find the high-quality goods following Red. This activity created a real and clear using scene and had a strong immersion. Through a series of interactive marketing activities, Red not only added the good opinion of consumers' and ignited consumers' sharing and consumption, but it also attracted new consumers in the process of disseminating interactive contents. Cooperated with interactive marketing its marketing strategy finally took the maximized effect.

\section{Results and Conclusions}

In mobile internet era, with the escalation of consumption the consumers' demands have changed significantly. As social e-commerce enterprises, they should adjust their marketing strategies to adapt to the consumer demand continuously. This paper studied the social e-commerce marketing strategies in detail. Firstly we summed up current research status about the social e-commerce. And hot issues discussed in the academia were the business model of social e-commerce, the influence to e-commerce consumers of socialization, studies of social e-commerce's communication effect and the social e-commerce marketing mode. Then we introduced SICAS model and analyzed "sense-interest-communication-action-consumption that is the consumer decision making process in +Web 2.0 mobile internet era" in detail. And based on this, we proposed a new social e-commerce marketing model, ICES model, combined with the consuming behavior in socialized era and the innovation in practice of social e-commerce's development. The new marketing model including content marketing, interactive marketing, experience marketing and sharing marketing and completely summed up social e-commerce enterprises' marketing strategy based on social media. The new marketing model emphasized the Omni-directional interaction between enterprise and consumers and satisfied consumers' emotion needs to promote consumption. Finally, this paper took Red, a social e-commerce APP, as the subject investigated, analyzed its marketing strategies by using the ICES marketing model which we proposed and summed up its successful experience. The results show that this marketing model has a high application value, and it can be used for reference for the domestic and foreign social electricity supplier enterprises.

\section{Acknowledgments}

Our research and paper are supported by Science and Technology Planning Project of Guangdong Province, China (2014A070703024). While remaining responsible for any errors in this paper, the authors would like to thank guidance and advice from all those who helped us in Jinan Univerrsity during the writing of this paper.

\section{References}

Afrasiabi, R. A., \& Benyoucef, M. (2011). A model for understanding social e-commerce. Journal of Information Systems Applied Research, 4(2), 63.

Barnes, S. (2015). Social Media Marketing: Like, Follow, Share-Social Media Marketing to Maximize Your Online Potential. Tycho Press.

Chen, W. Q. (2013). The spread of word of mouth in social E-commerce-a case study of mogujie.com and Meilishuo. News World, (5), 167-169. 
Data Center of China Internet. (2011). BLUEBOOK of Social Marketing Service. Retrieved from http://www.dcci.com.cn

Ding, Y. (2016). Red: Sea Amoy expert innovation. Shanghai Informatization, (1), 78-80.

Goldenberg, J., Lehmann, D. R., Shidlovski, D., \& Barak, M. M. (2006). The role of expert versus social opinion leaders in new product adoption. Journal of Marketing Research.

Jiang, J. (2012). A study on the effect of social e-commerce in China-a case study of Taobao (Doctoral dissertation, University of Electronic Science and Technology).

Kang, Y. R., \& Park, C. (2009, February). Acceptance factors of social shopping. In Advanced Communication Technology, 2009. ICACT 2009. 11th International Conference on (Vol. 3, pp. 2155-2159). IEEE.

Kim, Y. A., \& Srivastava, J. (2007). Impact of social influence in e-commerce decision making. International Conference on Electronic Commerce: the Wireless World of Electronic Commerce, 2007, University of Minnesota, Minneapolis, Mn, Usa, August (Vol. 258, pp. 293-302). DBLP. https://doi.org/10.1145/1282100.1282157

Lai, S. L. (2010). Social e-commerce-e-commerce in social media context. World Academy of Science Engineering \& Technology.

Li, H. (2014). The analysis of social e-commerce marketing model—a case study of Tencent. Today's Massmedia, (1), 60.

Li, J. (2014). Analysis on the Model of Social e-commerce Based on the Theory of Users"Information Behavior. Journal of the Graduates Sun Yat-Sen University (Humanities and Social Sciences Edition), (1), 63-72.

Liu, L. X. (2012). Research on Chinese Social e-commerce based on SNS. (Doctoral dissertation, Huazhong University of Science \& Technology)

Marsden, P. (2009). How social e-commerce works: The social psychology of social shopping. In Available at Social e-commerce today.com/ how- social- commerce- works- the-social- psychology of-social-shopping.: Social e-commerce Today, Syzygy London, London, UK.

Mata, F. J., \& Quesada, A. (2014). Web 2.0, social networks and e-commerce as marketing tools. Journal of Theoretical \& Applied Electronic Commerce Research, 9(1), 56-69. https://doi.org/10.4067/S0718-18762014000100006

Meng, F. (2012). Research of Opinion Leaders' Impact on Purchase Intention Under Social e-commerce(Doctoral dissertation, Nanjing University).

$\mathrm{Si}$, J. (n. d.) In order to allow users to buy, what has Red done? Mentor Business School. Retrieved from http://www.niaogebiji.com/article-13595-1.html

Song, X. (2015). Analysis of the "red" business model in the social network era. Business, (24), 80-80.

Srivastava, A., \& Pandey, K. M. (2013). Social media marketing: an impeccable approach to e-commerce. Management Insight, 8(2).

Wu, J. H., Gao, S., Mo, Z., \& Tao, L. (2014). Research on the Model Innovation of Social e-commerce. Journal of Modern Information (12), 48-52.

Xia, W., \& Lan, C. (2015). Research on the strategies for community e-commerce based on the mobile internet. Science Mosaic.

Zhang, A. L. (2016). Experience marketing in the application of e-commerce sites. Information Recording Materials.

Zhang, B., \& Liu, B. F. (2014). Research on Tourism micro-blog marketing model based on SICAS model. E-Business Journal, (11), 31-32.

Zhang, Y. M., Tang, C. S., \& Liu, H. (2014). The five marketing innovation rules of foreign social Electronic Commerce. E-Business Journal, (3), 30-31.

Zhu, X. D., \& Chen, J. (2016). A review of the research on social e-commerce in China. Journal of Modern Information, 36(1), 172-177. 


\section{Copyrights}

Copyright for this article is retained by the author, with first publication rights granted to the journal.

This is an open-access article distributed under the terms and conditions of the Creative Commons Attribution license (http://creativecommons.org/licenses/by/4.0/). 